\title{
Letter to the Editor: Histochemical Studies in Diastrophic Dwarfism
}

\author{
WILLIAM A. HORTON AND DAVID L. RIMOIN
}

Division of Medical Genetics, Harbor General Hospital, Torrance, California, USA

In their letter, Dr. Stanescu et al. pointed out that they have identified a number of cartilage abnormalities in diastrophic dwarfism and described them in detail before our recent article on the subject. We did not intend to imply otherwise. Our report concerned primarily observations made from a new tissue-processing technique which allowed us to perform extensive histochemical studies on undecalcified plastic embedded growth plate specimens. We felt that this approach provided new and useful histochemical information that was different from that obtained by other microscopic and microchemical methods. Our findings were described in detail, and the comments were relative to these observations. We apologize for failing to properly cite the important contributions in this area previously made by these investigators. 